\title{
Venuti, Lawrence. Contra Instrumentalism: a translation pole- mic. Lincoln: University of Nebraska Press, 2019, 216 p.
}

Ludmila Paiva ${ }^{1}$

${ }^{1}$ Universidade Federal do Ceará, Fortaleza, Ceará, Brasil

É reconhecida a importância da tarefa de tradução enquanto atividade essencial para as humanidades e as artes, bem como a sua relevância em diversos setores da sociedade. Apesar disso, como argumenta Venuti em Contra Instrumentalism: a translation polemic, o campo dos Estudos da Tradução vêm sendo grosseiramente mal entendido e explorado, tanto por estudiosos quanto pelo senso comum, pois a tradução é encarada como mera reprodução invariante e fixa, dependente do texto fonte. Deve-se a isso, acrescenta Venuti, a posição de inferioridade que os Estudos da Tradução ocupam diante de outros campos de estudo. A partir daí, como o título sugere, Venuti inicia a sua exposição propondo uma série de posicionamentos que devem ser reconsiderados dentro do campo dos Estudos da Tradução, deixando evidente, desde o início, que o alvo de sua argumentação é o instrumentalismo. Mas o que seria o modelo instrumentalista?

A fim de persuadir o leitor, Venuti polariza a atividade tradutória em dois campos: tradução hermenêutica e tradução instrumentalista. O modelo hermenêutico encara a tradução como um "ato interpretativo que inevitavelmente muda forma, efeito e significado do texto fonte de acordo com a inteligibilidade e interesses da cultura de chegada" (11). Trata-se do que Venuti enfatiza há tempos em seus trabalhos: a importância de que a tradução exige que o tradutor reinvente o texto 
fonte, de maneira que leve em consideração contextos culturais e políticos, tanto da cultura de partida, quanto da cultura de chegada.

Venuti afirma que o seu objetivo é pôr fim ao instrumentalismo que perpassa a teoria da tradução e do comentário. Segundo o autor, instrumentalismo é uma interpretação que simplifica grosseiramente a prática tradutória, adotando uma ilusão de acesso imediato ao texto fonte, na qual a tradução não passa de mera transposição mecânica de palavras de uma língua para outra. Venuti contrasta e pontua as contradições entre os dois modelos, a fim de justificar a importância do modelo hermenêutico em oposição ao instrumentalista. De acordo com o primeiro, adaptado da teoria semiótica de Charles Pierce e Umberto Eco, ao traduzir o tradutor utiliza-se de fatores interpretantes que podem ser fatores formais (que podem ser conceitos de equivalência ou estilos) e temáticos (como a interpretação do texto fonte presente em comentários). A aplicação de interpretantes garante que uma tradução seja relativamente autônoma do texto fonte, mesmo quando estabelece uma variedade de relações interpretativas com aquele texto. $\mathrm{O}$ autor salienta que o modelo hermenêutico oferece um compreensão abrangente da tarefa tradutória, bem como o papel dessa atividade nas instituições, imprimindo, enquanto ato interpretativo, compromissos éticos e políticos; pois toda tradução, independentemente de seu gênero, é um ato interpretativo que necessariamente inclui responsabilidades éticas e compromissos políticos (6).

A metodologia usada por Venuti para confrontar os modelos de tradução existentes baseia-se no método que Foucault chama de arqueológico, no qual ele interroga os vários discursos instrumentalistas, sempre cultural e historicamente situados, contrapondo-os com o modelo hermenêutico.

O livro inicia com um conjunto de frases provocativas, que são retomadas com o mesmo afinco no final e que, juntas, no decorrer de três capítulos, levam a um mesmo objetivo - o intuito de tecer 
reflexões polêmicas e expor um modelo que falha por procurar exaustivamente o erro e a intraduzibilidade. Para Venuti, a própria ideia do erro tradutório embasa as falácias do instrumentalismo, enquanto que o modelo hermenêutico possibilita uma pluralidade de interpretações e significados em um mesmo texto. Nesse sentido, ele categoricamente enfatiza a importância de entendermos todo texto como traduzível, pois todo texto pode ser interpretado e que "mesmo mantendo uma correspondência, a tradução constrói um conjunto diferente de contextos na língua traduzida, apoiando significados, valores e funções que são novos tanto para o texto original quanto para a cultura de recepção" (44).

No primeiro capítulo, Venuti afirma que a academia precisa urgentemente reconhecer que a tradução está no centro da pesquisa humanística, ou seja, que a tradução deve ser concebida com a carga ética e politicamente comprometida que a caracteriza. Ele aprofunda e detalha as maneiras pelas quais os estudos de literatura comparada nos Estados Unidos não avançam no que diz respeito à continuidade do modelo instrumentalista. Enfoca a posição inferior que os Estudos da Tradução ocupam na universidade e questiona quando os comparatistas irão admitir que os seus estudos dependem da tradução e "quando irão reconhecer que traduções contribuem para o entendimento do texto fonte pela simples razão de que se trata de interpretações e não de mera reprodução dos textos?". Aponta também como fator relevante o domínio da língua inglesa nas universidades americanas, diminuindo a importância da proficiência em língua estrangeira, e, consequentemente, a posição marginal que ocupam os dos Estudos da Tradução. Ele oferece, como alternativa para superar esse quadro, o modelo hermenêutico, o qual permite que traduções sejam lidas como textos, que se relacionam mas ao mesmo tempo diferem do texto fonte.

A técnica persuasiva na escrita de Venuti é a de confrontar e criticar o exemplos de trabalhos que perpetuam o que ele chama de instrumentalismo. De fato, nenhum dos exemplos escolhidos por 
ele no livro ganha mais destaque nessa experiência de embate do que Barbara Cassin e Emily Apter. Em relação ao The Dictionary of Untranslatables de Barbara Cassin, Venuti elogia a sua abrangência, ao mesmo tempo que salienta que "uma vez que os termos são repetidamente mal traduzidos na opinião de Cassin, chamá-los de "intraduzíveis" parece ser algo contraditório. Pois, em vez de demonstrar a intraduzibilidade, "as entradas documentam de fato uma sucessão de traduções, de modo que os termos revelam uma eminente capacidade de tradução" (54). Cada vez que um uma tradução é analisada como precisa, o modelo instrumentalista se manifesta pois assume que o texto fonte é invariante, fixo, o que Emily Apter define como "singularidade" (67).

Apter, de acordo com Venuti, ataca o que ela chama de forma fácil de tradução, que impulsiona o campo da literatura e que a noção dela de intraduzibilidade "é essencialista e não pode permitir um relato das contingências da tradução" (67), além de ser mais uma maneira de rebaixar os estudos da tradução incorporando um modelo instrumentalista (53). Venuti alega que a ligação de Apter com a teoria francesa torna as suas análises retrógradas, levando o campo de literatura comparada ao eurocentrismo característico do passado e que "Apter está interessada na teoria e não na tradução" (71). Acrescenta ainda que "capítulo a capítulo mostra que a exposição de Apter intensifica os efeitos questionáveis do instrumentalismo que ela herda do dicionário de Cassin" (66). Ele afirma ainda que Apter não traz à discussão o fato de que todo leitor imputa ao ato de ler uma inerente bagagem de experiências capaz de dar significado a cada palavra lida ou traduzida em um discurso crítico.

Venuti estende sua crítica à falta de comprometimento político de Cassin e Apter, pois, segundo ele, o ato de julgar traduções como corretas ou mal-feitas, impõe uma limitação dos significados, valores e funções que o texto fonte pode receber, levando à "supressão de possibilidades de mudança social e cultural (81)". 
Mais adiante, ao analisar o estudo de Weber e sua crítica à tradução de "a tarefa do tradutor" do texto de Walter Benjamin por Harry Zohn, Venuti pontua que Weber ao alegar que a tradução de Zhon não preserva o significado de Benjamin, ele também reproduz o modelo instrumentalista ao descartar o conceito de iterabilidade e que a sua interpretação particular reproduz uma possível semântica invariante contida no texto fonte.

O segundo capítulo contém uma abordagem estimulante acerca da tradução de provérbios. Venuti propõe um exame do gênero provérbio além de uma investigação de provérbios traduzidos e seus contextos de origem. Com o objetivo de desmascarar assertivas que ganharam espaço como verdade na tradução e mostrar como essas noções limitam o pensamento sobre o que a tradução é e faz, Venuti enfatiza que "ao longo de todo o capítulo a enfoque será nas relações entre o pensamento cliché e o modelo instrumental de tradução" (83).

Se, por um lado, a forma do provérbio é caracterizada pela invariância, o seu conteúdo é variante. Essa contradição entre forma e conteúdo faz do provérbio um exemplo do que Derrida, citado por Venuti, chamou de retrato da metáfora. A língua é metafórica, pois o signo linguístico não representa diretamente a realidade. $\mathrm{O}$ traço revelado pela abstração marca a característica metafórica do provérbio, que permite a sua "aplicação infinita ou posterior tradução em contextos heterogêneos" (85). De acordo com Venuti, na medida em que, no provérbio, a forma é traduzida em conteúdo, valorizando-o, o conteúdo se dissemina através da tradução posterior, desfazendo essa desvalorização, mas a forma a recupera interminavelmente. " $\mathrm{O}$ provérbio estabelece processos de tradução em curso que transformam os seus materiais de origem, seja de forma ou conteúdo, mas a transformação permanece invisível, impensável.” (87).

Entretanto, no que se refere à tradução, curiosamente, a relação do provérbio com o gênero muda. A invariância formal pode persistir, quer através da brevidade, quer através de uma repetitividade ou 
uma combinação destas características. Além disso, quando posto em prática, o provérbio é ainda reduzido ou traduzido numa abstração, o que revela a sua característica metafórica. Entretanto, o conteúdo não é variável. Venuti afirma que a tradução de provérbio é sempre vista como impossível de ser realizada.

Venuti confronta um trecho do célebre ensaio de Roman Jakobson On linguistic Aspects of Translation no qual Jakobson traz o exemplo "traduttore traditore" ao discorrer sobre a intraduzibilidade da poesia, pois, segundo Jakobson, ao traduzir o provérbio italiano para o inglês, perderíamos o ritmo e valores formais, porém acrescenta o questionamento sobre qual mensagem traduzir e de quais valores o tradutor seria um traidor. Segundo Venuti, Jakobson assume dois modelos de tradução: um modelo instrumentalista, ao imprimir a sua noção de intraduzibilidade poética, usando o provérbio para ilustrar a impossibilidade de reprodução de uma invariante formal que a tradução deveria ser capaz de transplantar mas não consegue, e um modelo hermenêutico, na medida em que propõe a resolução do problema da intraduzibilidade recorrendo à transposição criativa.

De acordo com Venuti, os impactos dos pressupostos instrumentalistas sobre o que a tradução é e faz são onerosos. O pressuposto da invariância formal e semântica rompe o pensamento sobre a tradução da mesma forma que rompe, no caso dos provérbios de tradução, a proliferação e disseminação de significados que tipificam o gênero do provérbio.

O terceiro e último capítulo retoma a presunção de fidelidade da legendagem. Apesar do notável crescimento nas últimas décadas de estudos, teses e cursos sobre legendagem, Venuti critica o fato de que a teoria tradutória ensinada nesses espaços acadêmicos permaneceram as mesmas, baseadas na transferência de significados, perpetuando o modelo instrumentalista. 
Segundo Venuti, há certa mistificação em torno do processo de legendagem, por falta de arcabouço teórico e de pesquisas sobre as práticas de tradução que dão origem a esse processo. Confrontando a afirmação de Jorge Díaz-Cintas e Aline Remael, de que o que determina o que deve ser ou não incluído na tradução é o balanço necessário entre o esforço do telespectador para processar um item e a relevância desse item para a compreensão do filme, Venuti considera instrumentalista esse pensamento, pois, segundo ele, deve-se levar em consideração o fato de que para decidir o que é relevante ou não, o legendador passa por um processo de interpretação, para então optar sobre o que necessita condensação ou omissão.

Venuti não oferece um caminho para esse impasse, mas defende que há necessidade de reflexão científica acerca das escolhas dos legendadores, afim de que se possa entender como esse processo ocorre. Venuti reclama da atual falta da resposta para a seguinte pergunta: "como as escolhas verbais dos tradutores contribuem para um tipo de interpretação que possa excluir outras possibilidades interpretativas?" (132).

Para ele, a legendagem mostra que a tradução constrói um contexto diferente e não menos complicado para o texto-fonte, o qual é reescrito na língua traduzida e adquire características constitutivas que podem suportar diferentes significados, valores e funções na cultura receptora. Acrescenta que o modelo instrumentalista dominante nas pesquisas sobre legendagem não leva esses fatores em consideração e que, por essa razão, não são capazes de analisar as conexões entre as escolhas verbais do tradutor e seus atos interpretativos. Venuti argumenta que apenas o modelo hermenêutico é capaz de "expor as múltiplas condições de uma tradução e evitar a mistificação que o instrumentalismo implica (172)”. Apesar da ênfase dada a essa necessidade, Venuti não propõe uma metodologia para encarar o processo tradutório de legendagem a partir do modelo hermenêutico. 
Venuti finaliza o capítulo assumindo que a tradução pode carregar certa correspondência semântica; entretanto, isso não acontece sem a variação que a interpretação introduz. Essas múltiplas interpretações possibilitam diferentes traduções. Uma tradução é um artefato cultural com os seus próprios materiais constitutivos e suas próprias formas de os processar e "isso é algo que devemos estudar, praticar e sim, aprender a desfrutar (172)."

O livro é repleto de referências e, apesar disso, Venuti é capaz de oferecer ao leitor um texto bem completo sem ser extenso e compacto sem ser simplista. A oposição binária entre modelo instrumentalista e hermenêutico não reduz as discussões à mera dualidade de polos. A seção denominada de "provocations" e seu conjunto de frases que fazem jus ao título, merecem ser exploradas dentro dos cursos de Estudos da Tradução. Entretanto, uma falha na argumentação de Venuti seria a sua ênfase na noção de um modelo de tradução superior ao instrumentalismo, através de confrontos que, segundo ele, são baseados em interpretações próprias, instrumentalistas, mas sem explicar metodologicamente o que seria esse modelo.

\section{Referências}

Venuti, Lawrence. Contra Instrumentalism: a translation polemic. Lincoln: University of Nebraska Press, 2019, 216 p.

Recebido em: 04/08/2020

Aceito em: 08/11/2020

Publicado em janeiro de 2021

Ludmila Paiva. E-mail: ludmilarodriguespaiva@gmail.com. ORCID: https:// orcid.org/0000-0001-6976-3055. 